\title{
Future ICT, AI, Computing and IoT in Support of Microbiology and Infectious Diseases Treatment
}

\author{
Eduard Babulak* \\ Maharishi University of Management, USA \\ *Corresponding author: Eduard Babulak, Maharishi University of Management, USA
}

Submission: 啙: 30 March, 2018; Published: 些 07 June, 2018

\section{Editorial}

Given the current globalization and mobility of people, in conjunctions with continuous increase of the world's population, degree of pollution, and climate change, the creation and spread of new kind of infectious diseases will have enormous impact on human health. In developing countries, the proper diagnosis and preventive measures are often subject to economic constraints and timely supply of necessary medications and medical equipment. To secure public health and proper medical support to people all over the world is becoming one of the most critical challenges for all mankind.

The governments in developing countries are under enormous pressure from their people who rightly demand proper provision of medical services and supply of proper and effective medication supply, in conjunction with healthy food, drinkable water, as well as the opportunities to farm and harvest live giving crops.

Due to ever increasing pollution and tragedies caused by natural phenomena, some of the most important commercial and nutritional fruit crops in the world are in danger. There is an ultimate connection between the medical care and agriculture. One way to advance research and innovation in pharmaceutical industry is the increase use of Artificial Intelligence and Smart Computation, parallel to massive medication production is a genetic manipulation through conventional techniques. However, any genetic medication manipulation by pharmaceutical industry, presents number of microbiological challenges and limitations. Most of the medications are very sensitive to light, temperature and moisture fluctuations and require particular time period for proper production process, long term storage and logistics distribution.

Countries in South East Asia, including Japan, South Korea are very conscious about preserving and human health and traditions of private access to medical care \& expert physician(s).

It is often spread of new infectious disease in the far remote areas that give rise to opportunities to establish proper diagnosis and consequently create a proper medication. With effective application of Smart Computing and AI in these remote and often underprivileged communities where new virus or disease occur, could be instrumental in identifying new infectious diseases and trigger a chain event based research, innovation and development of new live saving medications for billions of people worldwide.

In case of infectious diseases reaching borders of large cities via global mobility or natural phenomena, the application of effective vaccine and consequent medical treatment would be most effective. Unfortunately, there are many regions of the world, where Information Communications Technologies (ICT), AI and Smart Computation are underdeveloped due to economic or political constraints.

Good understanding and effective application of Microbiology fundamentals principles, in conjunction with proper application of ICT, AI and Smart Computation would contribute to creation of next generation of proactive health able to create new microbiological models, illustrating how the infectious diseases spread in the environment and human body, how genetic propagation of virus works, and how sequencing of the human genome may enhance the pharmaceutical research in support of combating the infectious diseases with effective medications. Current advancements in implementing microbiological databases provide a platform to model new unidentified disease diagnosis, with very sophisticated analytical tools to predict disease progression and potential healing processes. By definition, the Microbiology is a science living organisms [1].

Microbiologists interested in environmental, industrial and applied microbiology and, in general, scientists whose research fields are related to applied microbiology can find an overview of the current state of the art in the topic. In addition to the more general topic, some chapters are devoted to specific branches of microbiology research, such as bioremediation; biosurfactants; microbial factories; biotechnologically relevant enzymes and proteins; microbial physiology, metabolism and gene expression; and future bio industries [2-3].

The application of Microbiology is essential to human health, environment, agriculture, and effective medical treatment. Microbiology applications are used in a variety of fields: medicine and health, food-processing and chemistry, the environment, and agriculture. Microbiology is essential to modern medical treatment, 
human and animal health, regenerative medicine, synthetic biology, and environment. Given the current dynamic advancements in smart computing, AI, ICT, and the Internet of Things (IoT) may contribute to better healthcare and infectious diseases diagnostics and its spread monitoring. The advanced smart computing and ICT technologies, as well as mathematical tools could be effectively applied to global microbiological systems, public healthcare and environment.

The way we live and the way the humanity will continue to live on our wonderful Blue Planet is in the hands of all of us. Regardless of geographical location or, age, sex, education or position that one may have, we are all equally responsible for preserving life of our children, grandchildren and many generations to come after us. Apart from technological advancement in microbiology, biotechnology and bio-computing, the political will of decision makers to protect and preserve our wonderful Blue Planet for many future generations to come is critical.
The author discusses the importance of microbiology, ICT, AI and Smart Computing in support of identifying of new infectious diseases, and producing effective medications accessible to human in shortest possible delay. The author promotes application of microbiology, ICT, AI, Smart Computing, and IoT technologies in support of modern healthcare. The author also promotes further research and creation of global multidisciplinary research teams to build future sustainable microbiology and biotechnologies that will support public health for all mankind for many generations to come.

\section{References}

1. Google Research.

2. Current Research Topics in Applied Microbiology and Microbial Biotechnology.

3. Advances in Biotechnology and Microbiology, Juniper Publishers, USA
Creative Commons Attribution 4.0 International License

For possible submissions Click Here

\section{Submit Article}

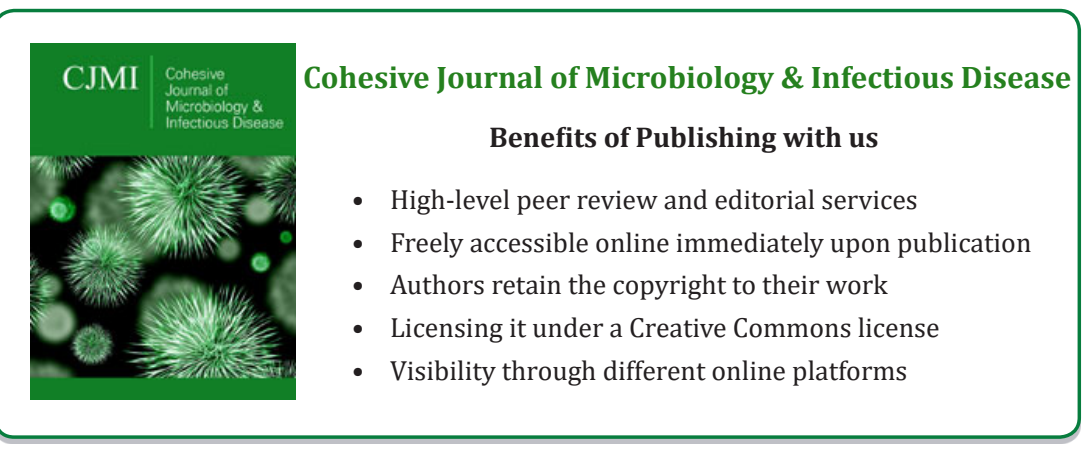

